\title{
Perception of E-Learning in Continuing Education by Midwives in Hospital Centers in the Casablanca-Settat Region
}

\author{
Amina LHBIBANI ${ }^{1,3 *}$, SaidLOTFI ${ }^{2}$, Malika TRIDANE ${ }^{1,4}$, Said BELAAOUAD $^{1}$ \\ ${ }^{1}$ Laboratory of Physical Chemistry of Materials, Ben M'sik Faculty of Sciences \\ Hassan II-Casablanca University (UH2C), Post box 5366 Maarif, Casablanca, Morocco \\ ${ }^{2}$ Evaluation in Sport Sciences \& Didactics of Physical Activity (ESSDAP), Superior Normal School (SNS) \\ Hassan II University-Casablanca (UH2C), Post box 50069, Street, Ghandi, Morocco \\ ${ }^{3}$ Higher Institute of Nursing and Health Technology Professions Casablanca- Settat \\ Street Faidouzi Mohamed, 20250 Casablanca, Morocco \\ ${ }^{4}$ Regional Center for Education and Training Trades Casablanca- Settat. Street Stendhal \\ Derb Ghallef Casablanca, Morocco
}

\begin{abstract}
In a context of strong competitiveness, E-learning is an innovative and emerging human resource development practice, now seen as a true future of vocational and continuing training. However, the need for continuing professional development is changing strongly and continues to growup. Traditional training systems and financial limitations do not meet all of the involving needs [1].
\end{abstract}

The main objective of this quantitative descriptive study is to determine the factors influencing the perception of E-learning and its usefulness in continuing education (CE) by midwives practicing at eleven hospital centers (CHP) in the CasablancaSettat region. Using a questionnaire inspired by Venkatesh's unified theory of acceptance and use of technology, Morris, Davis, \& Davis (2003), from a sample of 84 midwives [2].

The data are analyzed by ANOVA II. The results showed that the intent to use and the adoption of E-learning within the hospital centers in the first place, are significantly related to the perceived usefulness, perception of ease of use, the conditions facilitators and social influence ranging from 0.3 to 0.9 ( $p<0.05)$, towards continuing education through E-learning.

In conclusion, we hope, through this research, to show how the tools and the modes implemented in a distance-training program in a continuing education program could favor: the updating of knowledge and the improvement of skills of midwives.

Key words: Perception, E-learning, Continuing Education, UTAUT, Midwives

Received: 11 April 2019, Revised 8 July 2019, Accepted 2 August 2019

DOI: $10.6025 /$ jio/2019/9/4/109-118

(C) 2019 DLINE. All Rights Reserved 


\section{Introduction and Problem}

Continuing education of midwives is an essential component for the development of professional knowledge and skills in the workplace $[3,1,4]$. Research has highlighted its purpose and shows its usefulness in development. Knowledge, improved care in preventing maternal and neonatal mortality and morbidity.

However, the need for continuing professional development is changing strongly and is growing steadily. Traditional training systems and financial limitations do not meet the needs that are constantly changing [1]. Admittedly, no initial training program on its own can enable midwives to acquire the knowledge and skills they will need throughout their working lives [5].

Similarly, technological and scientific development, the extent of health needs for the reduction of maternal and infant mortality, and the renewal of clinical practices in gynecology and obstetrics based on convincing results, are all factors that justify the setting in place of an adapted and integrated strategy of continuing education responding to the national priorities and the aspirations of its health care staff [6].

Indeed, it is essential that midwives can extend and complete their training in a continuous way. With this, the emergence of information and communication technology (ICT) in the field of training has given birth to E-learning. Due to its flexible and flexible nature, it is a new essential approach to the benefits that it confers on the organization financially, socially and organizationally [7].

However, it is also worth mentioning that the increasing attention paid to digital technologies is forcing training institutions to better respond to the expectations of their caregivers, particularly midwives, by offering them training facilities adapted to this new situation, and integrating new opportunities for knowledge transfer [1].

In Morocco, continuing education is recognized as a right of all midwives and a duty of the administration. Continuing education programs for the latter are managed and funded by the Ministry of Health or independent hospital centers. Of course, in order to improve the health status of the population, the Ministry of Health has been engaged for about ten years in a vast project of reforms which has revealed a need for strategic alignment of training continues, which has materialized in the prioritization of human resources development through the reinforcement and development of their skills [8].Despite the initiatives undertaken by the Ministry of Health to train midwives, the organization of continuing education faces many organizational problems, including availability, in addition to genuine resistance to change, identification of needs and heterogeneous training, deficiencies in the quality of training, and in the monitoring and evaluation of training $[\mathbf{6}]^{1}$.

In this perspective, and to solve the problems of the continuing education of midwives and proceed to their permanent updating, to face the stakes of governance and constant evolution of the technology, the knowledge and the competences required by better and more efficient health system, all these elements argue in favor of the adoption of E-learning as a mode of education in the continuing education of midwives.

All these findings led to a study to determine the factors influencing the perception of E-learning in continuing education by midwives in the Casablanca-Settat region. Our problem is to answer the following questions:

- What is the degree of knowledge of E-learning training by midwives?

- What are the potential factors of the intention to accept and use E-learning training in continuing education for midwives?

\section{Literature Review}

In this part, we will start by identifying and defining the concepts constituting the basis of our study, before exposing the theoretical framework that will serve us as a reference in the literature. Few studies have addressed the subject of the evolution of E-Learning in continuing education in nursing, despite its advantages and its usefulness its deployment in professional circles remains limited compared to the field of education and teaching $[\mathbf{9 , 1 0 , 7 ]}$.

\subsection{Theoretical Foundation}

The behavior of the individual with regard to the technology has strongly interested the researchers in information system.

110 Journal of Information Organization Volume 9 Number 4 December 2019


Thus, several models have been developed to explain and predict the behavior of individuals in the use of information and communication technologies. The theoretical foundations of these models are drawn from research in social psychology. The most used theories are reasoned action theory (Ajzen and Fishbein, 1975), planned behavior theory (Ajzen, 1985) [11, 12], technology acceptance model (Davis, Bagozzi, \&Warshaw, 1989) and the unified theory of acceptance and use of technology (Venkatesh and al., 2003) [13, 2].

\subsection{Unified Theory of Acceptance and use of Technology}

The Unified Technology Acceptance and Use Theory (UTAUT) of Venkatesh and al. (2003) is in the family of models of the explanation of intent to accept and use technology [2]. UTAUT is in the family of intent models and focuses on the individual value of technology acceptance. UTAUT considers the intention to adopt a technology and its use as two dependent variables and examines their determinants. Compared to previous theories, this theory highlights two aspects: the synthesis of determinants from other research models for the development of one's own and the consideration of moderating variables to mitigate the influence of determinants on intention and the behaviour.

According to Venkatesh and al. (2003), the influence of the usage context (voluntary or mandatory) has a significant effect on the adoption of technologies. When this context is mandatory, determinants from social influence have a stronger effect. Similarly, the effect of different determinants of intention varies over time. The addition of the experience variable is significant on the measurement of some determinants and different on others. The explained variance of the determinants of intention and use increases considerably with the addition of the moderating variables "Age" and "Sex" [2].

The synthesis of the UTAUT makes it possible to retain:

- Perceived usefulness, perceived ease of use, and social influence as direct determinants of intention;

- Facilitating conditions and intention to adopt behavior as direct determinants of use;

-Age, sex, experience and context of use (voluntary or mandatory) as moderating variables.

\section{Research Model -terms of Reference}

The research model designed for this study relies mainly on the UTAUT of Venkatesh and al. (2003) previously described. The choice of this model is based on its great explanatory power of the intention to use a technology and the fact that it contains a large number of constructs that interest us to explain the individual decision to use the "E- learning "in continuing education by the midwife. Four basic variables define this model of Venkatesh and al. (2003) namely: - perceived ease of use, - perceived utility, - Social influences- And the enabling conditions.

\subsection{The Intention of use}

When a midwife expresses her an intention to participate in an E-learning device, this indicates that she considers E-learning as acceptable in a context of continuing education. Usage intent is defined here as an indicator of acceptability.

We seek to know the links between the intention of use and the four main variables: perceived utility, perceived ease of use, social influences, enabling conditions, moderated by demographic factors, age and sex, a related factor to the previous experience of E-learning and also a contextual factor which is the obligation to participate in an E-learning device.

Indeed, we specify that the four variables of the UTAUT model are able to explain a large part of the intention to use E-learning.

\subsection{Perceived ease of use}

Davis (1989) as «The intensity with which an individual believes that the use of a particular system will be without difficulty or additional effort» defines it [14]. According to Venkatesh and al. 2003 "This is the degree of ease associated with using a system [2]. Our study proposes to describe the effect of the ease of use perceived by the midwife to use E-learning technology in continuing education. The resulting hypothesis is:

H1: Perceived ease of use has a significant effect on the adoption intent of E-learning. 


\subsection{Perceived Utility}

The concept of perceived utility had a very powerful predictive power and it had proved its robustness in explaining usage behavior across many studies. In the field of information systems, it is the "degree to which an innovation is perceived as offering a greater advantage than the practice» [15].

The relative advantage seems to be considerable importance in persuading individuals to adopt an innovation. From another point of view, the midwife can only accept E-learning in a care facility if she perceives its usefulness in relation to continuing education needs and its effect in terms of earnings performance and productivity, and is convinced that this new technology will help it evolve and be more efficient. Perceived usefulness is thus considered as a determining factor in the adoption of Elearning in continuing education by the midwife, and will serve to evaluate the perception of the utility generated by the adoption of this technology.

\section{H2: Perceived usefulness has a significant effect on the intention to adopt E-learning.}

\subsection{Social Influences}

With regard to social influences, which include subjective norms, social factors and the expectation of valorization, only the dimension "subjective norms" suggested by Ajzen and Fishbein (1975) in the theory of reasoned action [11] and taken into account by Venkatesh and Davis (2000) [16] in the extension of the technology acceptance model (MAT) and by Venkatesh and al. (2003) in UTAUT was selected [2].

This construct concerns the importance of the views of the social group in forming the intention to use a new system. It is then preferable to appreciate the influence of certain sources in a distinctive way, considering the influence of the colleagues, the general management and the expectation of valorization.

\section{H3: Social influences have a significant effect on the intention of adoption of E-learning}

\subsection{Facilitating Conditions}

Venkatesh and al. (2003) defines facilitating conditions as "the degree to which the user believes that the organizational and technical infrastructure is necessary for the use of the system". According to Venkatesh and al. (2003), facilitating conditions directly influence the behavior of use, without the influence of intention to behave [2].

\section{H4: The enabling conditions have a significant effect on the intention to adopt E-learning.}

\section{Methodology}

This research is descriptive and quantitative.

\subsection{Field of Study}

The study was conducted at twelve prefectural / provincial hospital centers (CHP) in the Casablanca- Settat region (one of the 12 national regions) during the month of April 2018. It focuses on the factors influencing the perception of E-learning in continuing education by midwives. The choice of these hospitals in this region is justified by the significant performance in the production of care in terms of monitoring of pregnancy and delivery provided by midwives who are: 43677 deliveries, including 29471 normal deliveries and 4205 obstructed deliveries, and 10001 cesarean deliveries [17]. With this in mind, improving the supply of maternal and newborn care at all levels of care through continuing education for midwives play a key role in reducing maternal and neonatal mortality and morbidity, and in promoting the health of women and children.

\subsection{Sample}

The target sample of the study is the midwives practicing in the CHP of the Casablanca-Settat region. The size of this sample was set at 84 (53.84\% of the population), it is an accidental nonprobability sampling (or convenience). Response rate: $100 \%$.

\subsection{Measuring Instruments}

Through the UTAUT research model of Venkatesh and al. (2003), we used a questionnaire with 35 questions, divided into three sections:

112 Journal of Information Organization Volume 9 Number 4 December 2019


- Midwives profile of Information and Communication Technology (the computer and the Internet);

- Knowledge and potential factors influencing the perception of E-learning in continuing education by midwives;

- General data on the profile of midwives.

The questions are measured by the 5-point Likert scale from "Strongly disagree" to "Totally agree". We pre-tested the questionnaire with volunteer midwives who were not in the sample to adjust before final use.

\subsection{Data Analysis Method}

The results from the UTAUT variables are presented in the form of means, standard deviations in Table 1. We used ANOVA of 2-factors to determine the effect of the moderating variables: age, profile, function, seniority, and their interaction on the average scales of perception of E-Learning. Posthoc analyzes are performed by the Bonferroni test. The correlation between the scores of the scales is calculated by the correlation coefficient of Bravais Pearson and the reliability of these is expressed by Cronbach's alpha, $p$ is fixed at 0.05 (Table 2 and 3). The data is processed by SPSS (IBM Corp. Released 2012. IBM SPSS Statistics for Windows, Version 22.0, Armonk, NY: IBM Corp.).

\subsection{Ethical Considerations}

The study was conducted after the approval of the directors of the various hospitals in the Casablanca-Settat region. The consent of the participants was also obtained. They were reassured that their answers would remain confidential and their identities would not be revealed in research reports and publications.

\section{Results}

\subsection{Analysis of the reliability of scales of perception of E-Learning}

The analysis of the reliability of the scales of perception of E-Learning, is presented in Table 1 and 2.

\begin{tabular}{|l|c|l|c|c|}
\hline Variables (constructed) & Number of Items & Mean & 士 Standard deviation & Alpha de Cronbach \\
\hline $\begin{array}{l}\text { Mean Intention to Adopt } \\
\text { E-Learning }\end{array}$ & 6 & 3,72 & 1,03 & 0.880 \\
\hline Average Perceived Utility & 3 & 3,36 & 1,51 & 0.987 \\
\hline Average Perceived ease of use & 4 & 3,46 & 1,41 & 0.974 \\
\hline Average Social Influences & 3 & 3,44 & 1,49 & 0.967 \\
\hline Average facilitating conditions & 3 & 3,56 & 1,42 & 0.953 \\
\hline Total & 19 & 3.53 & 1.44 & 0.967 \\
\hline
\end{tabular}

Table 1. Internal consistency of theoretical constructs by Cronbach á coefficient

The Cronbach Alpha test that we used allowed us to measure the reliability of UTAUT's E-Learning perception scales, if they are supposed to measure the same construct. In principle, the values obtained vary from 0 to 1 . The closer the value is to 1 , the higher the internal coherence between items of the same scale. Thus, in our results, all calculated values are above the recommended 0.80 threshold [18]. All the items in the 5 scales are sufficiently inter-correlated: the internal validity of the questionnaire is therefore satisfactory (Table 1). Indeed, we kept all the items in our questionnaire for our study.

\subsection{Analysis of the Correlation of the scales of Perception of E-Learning}

Cross-scale correlation analysis shows that in all ten calculated relationships, all correlation coefficients are significant and positive ranging from 0.3 to $0.9(p<0.05)$, which is $100 \%$ of calculated relationships. These are generally moderate to raise (Table 2). 


\begin{tabular}{|c|c|c|c|c|c|c|}
\hline & & $\begin{array}{l}\text { Average inten- } \\
\text { tion of adoption } \\
\text { E-learning }\end{array}$ & $\begin{array}{l}\text { Average } \\
\text { perceived } \\
\text { utility }\end{array}$ & $\begin{array}{l}\text { Average } \\
\text { perceived } \\
\text { ease of use }\end{array}$ & $\begin{array}{l}\text { Average } \\
\text { Social } \\
\text { Influences }\end{array}$ & $\begin{array}{l}\text { Average of } \\
\text { the facilitating } \\
\text { conditions }\end{array}$ \\
\hline $\begin{array}{l}\text { Average intent of } \\
\text { adoption E-learning }\end{array}$ & $\mathrm{r}$ & 1 & & & & \\
\hline \multirow{2}{*}{$\begin{array}{l}\text { Average perceived } \\
\text { utility }\end{array}$} & $\mathrm{r}$ &, $541 * *$ & 1 & & & \\
\hline & $\mathrm{p}$ & ,000 & & & & \\
\hline \multirow{2}{*}{$\begin{array}{l}\text { Average perceived } \\
\text { ease of use }\end{array}$} & $\mathrm{r}$ &, $514 * *$ &, $987 * *$ & 1 & & \\
\hline & $\mathrm{p}$ & ,000 & ,000 & & & \\
\hline \multirow{2}{*}{$\begin{array}{l}\text { Average Social } \\
\text { Influences }\end{array}$} & $r$ &, $500 * *$ &, $973 * *$ &, $962 * *$ & 1 & \\
\hline & $\mathrm{p}$ & ,000 & ,000 & ,000 & & \\
\hline \multirow{2}{*}{$\begin{array}{l}\text { Average of the } \\
\text { facilitating conditions }\end{array}$} & $\mathrm{r}$ &, $307 * *$ &, $748^{* *}$ &, $770 * *$ &, $751 * *$ & 1 \\
\hline & $\mathrm{p}$ & ,004 & ,000 & ,000 & ,000 & \\
\hline
\end{tabular}

Table 2. Correlation matrix expressed by the Bravais Pearson coefficient

\begin{tabular}{|l|l|l|l|l|l|l|l|l|}
\hline $\begin{array}{l}\text { Perception of } \\
\text { E-learning }\end{array}$ & $\begin{array}{l}\text { Effect } \\
\text { Age (Ag) }\end{array}$ & $\begin{array}{l}\text { Effect } \\
\text { Profile (P) }\end{array}$ & $\begin{array}{l}\text { Effect } \\
\text { Function (F) }\end{array}$ & $\begin{array}{l}\text { Effect } \\
\text { Seniority (S) }\end{array}$ & \multicolumn{4}{|c|}{ Interaction Effect } \\
\hline $\begin{array}{l}\text { Average intent of } \\
\text { adoption E-learning }\end{array}$ & 0.001 &, 005 & $\mathrm{~ns}$ & $\mathrm{~ns}$ & $\mathrm{~ns}$ & $\mathrm{~ns}$ & $\mathrm{~ns}$ & $\mathrm{~ns}$ \\
\hline $\begin{array}{l}\text { Average perceived } \\
\text { utility }\end{array}$ & 0.000 &, 000 & $\mathrm{~ns}$ & 0.000 & $\mathrm{~ns}$ & $\mathrm{~ns}$ & $\mathrm{~ns}$ & $\mathrm{~ns}$ \\
\hline $\begin{array}{l}\text { Average perceived } \\
\text { ease of use }\end{array}$ & 0.000 &, 000 & $\mathrm{~ns}$ & 0.000 & $\mathrm{~ns}$ & $\mathrm{~ns}$ & $\mathrm{~ns}$ & $\mathrm{~ns}$ \\
\hline $\begin{array}{l}\text { Average social } \\
\text { Influences }\end{array}$ & 0.000 &, 000 & $\mathrm{~ns}$ & 0.000 & $\mathrm{~ns}$ & $\mathrm{~ns}$ & $\mathrm{~ns}$ & $\mathrm{~ns}$ \\
\hline $\begin{array}{l}\text { Average of facilitating } \\
\text { conditions }\end{array}$ & 0.023 &, 000 & 0.000 & 0.000 & $\mathrm{~ns}$ & 0.025 & $\mathrm{~ns}$ & $\mathrm{~ns}$ \\
\hline
\end{tabular}

Table 3. Effect of age, profile, function and age factors and their interaction on perception parameters of E-learning (ANOVAII)

\section{$r$ : Correlation of Pearson, $p$ : Probability of Significance, $N$ : number**. Correlation is significant at 0.01 level (bilateral), *} significant at 0.05 level.

Variation of the factors influencing the perception of E-Learning according to the characteristics of the respondents (Table 3).

\section{Effect of age}

The statistical analysis revealed by ANOVA, shows that the age exerts a significant effect $(p<0.05)$, but with weak effect of size (Eta: 0.1 to 0.3 ) on the variation of the scores at the level of the intention adoption, perceived usefulness, ease of use, social influences of E-learning in continuing education, especially the age group between 31 to 40 years, as well as the enabling 
conditions (51 to 59 years).

\section{Effect of Profile}

The profile of the respondents significantly differentiated $(p<0.05)$ the scores of the 5 scales. Indeed, midwives express more than the midwives their intention to use E-learning $(3.90 \pm 1.04$ vs $3.18 \pm 0.77)$, also for the perceived usefulness of E-learning in continuing education ( $4.04 \pm 1.06$ vs $1.32 \pm 0.47)$, ease of use of E-learning ( $4.09 \pm 0.98$ vs $1.56 \pm 0.44)$ and finally social influences for the use of E-learning $(4.17 \pm 0.87$ vs $1.24 \pm 0.34)$. We also observed a significant interaction effect between the profile and effect of age at the level of the facilitating conditions of E-learning.

\section{Effect of the Function}

We also noted that midwives practicing in delivery rooms significantly demonstrate the importance of the facilitating conditions of E-learning in continuing education, compared to nurse nurses in positions of responsibility, but with a low size effect (Eta: 0.305).

\section{Effect of Seniority}

Seniority in the work place has significant effects on the variations of E-learning scores with average size effect (Eta: 0.24 to 0.44) in terms of perceived utility, ease of use, social influences and the facilitating conditions. The higher scores are observed at the level of (6 months to 1 year) of experience and progressively reduced according to the number of years spent in the job (more than 10 years). However, the decision to use E-Learning in the continuing education is not modified by this effect.

$p$ : probability of Significance, $*$ : significant effect at the 0.05 level, **: very significant effect at the 0.01 level***: highly significant effect at the 0.001 level

\section{Discussion}

Continuing education through E-learning is an innovative and emerging human resources development practice. It has several financial, social and organizational benefits. Through this study, we saw the perception of the acceptance and use of electronic training in continuing education with 84 midwives from different hospitals in the region of Casablanca-Settat; we exploited the model of UTAUT as a measuring instrument. The results obtained will be discussed in light of the problematic and the literature review.

The statistical analysis showed a statistically significant correlation between the variable of perceived utility and the intention of adoption of E-Learning in continuing education. This utility manifests itself primarily in the perception of the performance gains resulting from the use of the method. These gains translate into the acquisition of new knowledge necessary for the execution of tasks and the improvement of the level of skills held.

Similar to a large number of studies by researchers who have adopted the UTAUT model, they have shown that perceived usefulness is the main determinant of intention to use a technology [19, 20, 21, 22].

In the works of Vankatesh and al. (2003), this variable was judged significant by the importance of the learner's perception of the benefits he or she expects to derive from his use of a technology on his intention to use this technology.

On the other hand, in Yuen \& Ma's (2008) study of 280 teachers participating in a professional E-learning training platform set up by the University of Hong Kong, researchers do not find significant link between perceived utility and usage intent [23].

In our study, the relationship between perceived ease of use and the intention to adopt E-Learning is statistically significant, particularly the group age between [31-40 years old [with an average of $(3.91 \pm 1,29)$.

It depends directly on the availability and mastery of ICTs that also affect intent [1]. Very often, it is a determining factor in the intention to use a technology, but more specifically in start of use, in the discovery phase. The more time passes, the less the link is strong, it will even disappear when the use becomes routine [23, 24].

This is perfectly in line with the work of Venkatesh and al. (2003), however the effect would also be greater in relation to gender, age and experience: the results of their studies show that perceived ease of use is the main determinant for women, older, and 
those with a little experience of the system studied [2].

In contrast, our results are significantly different from those of Lassoued (2010) perceived ease of use is the main determinant for age categories between 36 to 50 years and not for those over 50 years. Sex then does not intervene as moderator [21].

Adding to this study conducted by Mokhtar (2008) advocated that nurses represent the category of health professionals who have the least access to information and communication technologies have a low level of use [1].

The explanations advanced for this fact are related to the demand of their work that does not require this technology. This could explain their low proportion of perceived ease of use of E-learning. In fact, the midwife who thinks that she is capable of use this technology will have favorable perceptions of the efforts made to be able to benefit from it. The E-learning device will not be complex; therefore, the adoption of this technology would be highly probable.

As far as the social influences variable is concerned, it encompasses several dimensions: the subjective norm (which I believe the people important to me would think of me if I participated in a device in E-learning), a socio-professional factor (what I think the social group I belong to would do), and the image (if I believe that participation in an online device will improve my image visà-vis the social group.).

The results of the study Venkatesh and al., (2003) show that these factors are significant only when the use of a system is mandatory, and conforming to the usage is then experienced as a result of social pressure. The influence of society gradually diminishes over time [2]. In other words, the more a person acquires experience, the less social influence is felt, even if use is forced at the outset [24].

In our study, the statistical analysis of the existence of a positive and moderate statistical correlation between the latter and the intention of adopting E-Learning in continuing education.

Moreover, in our research, the link between the influences of colleagues and superiors on the one hand, and the intention of adoption of E-learning on the other hand was significant. Also, the self-image variable indicates that the midwife associates the improvement of her image with the adoption of E-learning through continuing education. For her, the use of this technology provides a professional added value to her colleagues and superiors, hence the confirmation of the proposition that the selfimage has a significant effect on the intention to adopt the E- learning [2-1].

This is confirmed on the one hand with the results of the study conducted by Lassoued (2010) who confirmed the existence of a significant link with the intention to participate in a device in E-learning, both for staff who already had the experience for others [21].

And on the other hand with the study conducted by Mokhtar (2008) who has shown that self-image is another influencing factor on the intention of use of E-learning by health professionals. This could be explained by the inequity of the distribution of continuing education between professionals and that it is the same people who benefit from it and who can be seen by their peers as superior to others who do not do not benefit [1].

We can predict from the results of our study that this observation is related to the reality of the management of continuing education, which is marked by its constraining verticality that does not take into account the real needs of nurses, in addition to the slowdown in its rhythm and inequity in its distribution [25]. Hence, the need to have a new vision for the management of continuing education so that it is more equitable and adapted to the needs [1].

For the variable enabling conditions and the intention of adoption of E-Learning is statistically significant, this variable includes the availability of the necessary resources in terms of hardware, internet connection, and also in terms of technical assistance which assumes the existence of a resource person available to deal with any difficulties that the learner may encounter during his learning process. The need for the midwife to be assisted in case of difficulty respectively determines the adoption of Elearning and the motivation to continue to follow E-learning courses.

Among the characteristics, age and profile are factors that have moderated the intention of using E-learning midwives, this finding is consistent with data from the literature indicating that the older the user the better the chances of use Information and

116 Journal of Information Organization Volume 9 Number 4 December 2019 
Communication Technology, decrease [1-26]. This suggests that young health professionals are more open to technology. However, the effect of gender does not have an effect on the intention of adopting E-learning in the continuing education of midwives is due to the context and the nature of the vocational training of midwives in Morocco, which is purely reserved for the female gender.

Concerning the function and seniority, variables have no effect on the intention of adoption of E-learning in the continuing education of midwives. However, the perceived ease of use influence on the intention to participate in a device in E-learning is moderated by gender and age.

\section{Limit of the Study}

One of the limits of our study is related to the research instrument used, the fact of being limited to the questionnaire with closed questions gave us some subjectivity in the answers obtained, which did not give the opportunity to deal with some data It would also be interesting to be able to confirm these results by using a larger sample or an exhaustive survey of all categories at the different hospital centers in order to identify any differences or similarities between the different categories.

\section{Conclusion}

The analysis of the results allowed us to identify the factors influencing the perception of the adoption of E-learning in continuing education, and which are: perceived utility, perceived ease of use, enabling conditions and social influences. In addition, our results provided indications for possibly implementing this technology in the field.

At the end of this research, it would be relevant to recall the need to open other avenues of research in different hospitals and with other individual, social and organizational variables in order to better facilitate the integration of technology in the daily field practices of different health professionals......

\section{Declaration of Interest}

The authors declare that they have no links of interest.

\section{References}

[1] Mokhtar, H. (2008). Using E-learning in continuing education in health: A point of view of health professionals. Thesis submitted for the degree of master's degree in health administration and public health.

[2] Venkatesh, V., Morris, M. G., Davis, G. B., Davis, F. D. (2003). User Acceptance of Information Technology: Toward a Unified View, MIS Quarterly, 27(3), 425-478 - Available at: https://www.google.com/search

[3] Abbatt, F. R., Mejía, A. (1990). WH Organization. Continuing Education of Health Personnel: Manual for Workshops. Geneva: Geneva: World Health Organization; 1990. Available at: http://apps.who.int/iris/handle/10665/39499.

[4] HAS. (2014). Life-long vocational training of allied health professionals. Continuing Professional Development (CPD) Method Sheet -Available at: https://www.google.com

[5] OIIQ. (2011). Towards a culture of continuing education for the nursing profession in Quebec Montreal: Order of Nurses of Quebec.

[6] Ministry of Health. (1999). The standards of continuing education. Rabat.

[7] Messaoudi, F. (2013). e-learning devices: what uses to improve training in Morocco? from the first national barometer of elearning to the case study of continuing education.

[8] Action Plan (2008-2012). - Google Search [Internet]. Available at: https://www.google.com/

[9] Guerrero, S. (2001). Contribution to the effectiveness of E-learning, IAS Symposium, Toulouse, August 30 and 31, p. 161-167.

[10] Naoui, N. B., Gaha, C. Assaad EL AKREMI. Higher Institute of Management of Tunis Catholic University of Louvain / IAGREHU. : 17. The determinants of use of electronic training: approach by theories of technology adoption empirical analysis in the Tunisian context. https://basepub.dauphine.fr/bitstream/handle/123456789/2076/ben\%20naoui.pdf;sequence=2 
[11] Fishbein, M., Ajzen, I. (1975). Belief, attitude, intention, and behavior An introduction to theory and research. Reading, MA Addison-Wesley. - References - Scientific Research Publishing. Available at: http://people.umass.edu/aizen/e\&a1975.html

[12] Ajzen. I. (1985). From intention to action: a theory of planned behavior, in Kuliland, J, Beckman, J, action control: from cognition to behavior, Springer, Heidelberg, p.11-39.

[13] Davis, F. D., Bagozzi, R., Warshaw, P. R. (1989). User acceptance of computer technology: a comparison of two theoretical models, Management Science, 35(8) (August), 982-1003.

[14] Davis, F. D. (1989). Perceived usefulness, perceived ease of use and user acceptance of information technology, MIS Quarterly, 319 - 339. - Google Search Available at: https://www.google.com/search

[15] Moore, G. C., Benbasat, I. (1991). Development of an Instrument to Measure the Perceptions of Adopting an Information Technology Innovation. Information Systems Research, 2 (3) 192-222. doi: 10.1287 / isre.2.3.192.

[16] Venkatesh, V., Davis, F.-D. (2000). A theoretical extension of the technology acceptance model: four longitudinal studies, Management Science, 46(2) (February), 186-204.

[17] Health in figures-2015, Edition 2016. Directorate of Planning and Financial Resources Division of Planning and Studies. Department of Studies and Sanitary Information. Morocco.

[18] Peterson. (1995). A meta-analysis of Cronbach's alpha coefficient - Robert A. Peterson, 1995. Research and Applications in Marketing, X (2). Available at: https://journals.sagepub.com/doi/abs/10.1177/076737019501000204

[19] Manon, B. (2007). Use of the technology acceptance model among professionals interested in virtual reality as a therapeutic tool. what are the factors influencing their decision? Université du Québec à Montréal library service. Availableat: https:// www.google.com/search?

[20] Marchewka, J. T., Liu, C., Kostiwa, K. (2007), An Application of the UTAUT Model for Understanding Student Perceptions of Course Management Software, Communications of the IIMA.

[21] Lassoued, T. (2010). The determinants of the adoption of e-learning: an empirical study within the Tunisian company. University of Lyon 3: Thesis 7(2) 93-104.

[22] Wamba, S. F., Yombia, S. M. K., Kamdjoug, J. R. K. (2019). Factors favoring the acceptance and use of ICT in companies: the case of the CNPS. [cited 24 Jan 2019]; Available at: $h$ ttps://www.academia.edu/29525815/The_factors_promising_the_acceptance _and the_use_of_the_CNPS_in_corporate_business.

[23] Yuen, A.H., Ma, W. W. (2008). Exploring teacher acceptance of e-learning technology. Asia Pacific Journal of Teacher Education, 36 (3).

[24] Christine Nucci-Finke. (2015). Teachers and e-learning Factors of adoption or rejection of e-learning, in a context of teacher training Thesis - Google search. Available at: https://www.google.com.

[25] Gruenais, M. E., Rachih, N., Bousbaa, A., Houssam, T., Khalil, J., D E Brouwere, V. (2008). A qualitative approach to the question of the demotivation of health personnel. The point of view of the actors of the Greater Casablanca health region Rabat, INAS; April 2008.

[26] Lauzon, N. (2003). e-learning, practices and organizational policies in business, Distances and Knowledge 2003/4, 1, 471488. 